\title{
Meteorological and climatic variables predict the phenology of Ixodes ricinus nymphs activity in France, accounting for habitat heterogeneity
}

Phrutsamon Wongnak

Université de Lyon, INRAE, VetAgro Sup, UMR EPIA

Maude Jacquot

Université Clermont Auvergne, INRAE, VetAgro Sup, UMR EPIA

Séverine Bord

Université Paris-Saclay, INRAE, UMR MIA-Paris

Albert Agoulon

INRAE, UMR BIOEPAR

Frédéric Beugnet

Global Technical Services, Boehringer-Ingelheim Animal Health

\section{Laure Bournez}

ANSES, Nancy Laboratory for Rabies and Wildlife

Nicolas Cèbe

Université de Toulouse, INRAE, UR CEFS

Adélie Chevalier

INRAE, UR EFNO

Jean-François Cosson

ANSES, ENVA, INRAE, UMR 956 BIPAR

Naïma Dambrine

Université de Lyon, INRAE, VetAgro Sup, UMR EPIA

Thierry Hoch

INRAE, UMR BIOEPAR

Frédéric Huard

INRAE, US 1116 AgroClim

Nathalie Korboulewsky

INRAE, UR EFNO

Isabelle Lebert

Université Clermont Auvergne, INRAE, VetAgro Sup, UMR EPIA

Aurélien Madouasse

INRAE, UMR BIOEPAR

Anders Mårell

INRAE, UR EFNO

Sara Moutailler

ANSES, ENVA, INRAE, UMR 956 BIPAR

Olivier Plantard

INRAE, UMR BIOEPAR

Thomas Pollet

ANSES, ENVA, INRAE, UMR 956 BIPAR

Valérie Poux

Université Clermont Auvergne, INRAE, VetAgro Sup, UMR EPIA

Magalie René-Martellet

Université de Lyon, INRAE, VetAgro Sup, UMR EPIA

Muriel Vayssier-Taussat

ANSES, ENVA, INRAE, UMR 956 BIPAR

Hélène Verheyden

Université de Toulouse, INRAE, UR CEFS

Gwenaël Vourc'h

Université Clermont Auvergne, INRAE, VetAgro Sup, UMR EPIA

Karine Chalvet-Monfray ( $\sim$ karine.chalvet-monfray@inrae.fr)

Université de Lyon, INRAE, VetAgro Sup, UMR EPIA 


\section{Research Article}

Keywords: Ixodes ricinus ticks, Habitat characteristics, Meteorological conditions, Phenological patterns, Questing activity

Posted Date: December 29th, 2021

DOI: https://doi.org/10.21203/rs.3.rs-1195681/v1

License: (c) (i) This work is licensed under a Creative Commons Attribution 4.0 International License. Read Full License 


\section{Abstract}

Ixodes ricinus ticks (Acari: Ixodidae) are the most important vector for Lyme borreliosis in Europe. As environmental and climate changes might affect the distribution and activity of tick populations, this study aimed to determine the effects of environmental factors, i.e., meteorological, bioclimatic, and habitat characteristics on questing activity of I. ricinus nymphs across diverse climatic types in France over an 8-year period. Questing activity was observed using a repeated removal sampling design with a cloth-dragging technique in 11 sampling sites from 7 tick observatories from 2014 to 2021 at approximately 1 month intervals, involving 631 sampling campaigns. Three phenological patterns were observed, potentially following a climatic gradient. The mixed-effects negative binomial regression revealed that observed nymph counts were driven by different interval-average meteorological variables, including one-month average temperature, previous-season average temperature, and half-year average minimum relative humidity. The interaction effects indicated that the phenology in colder climates peaked differently from that of warmer climates. Also, the land cover characteristics that support the highest baseline abundance were moderate forest fragmentation with transition borders with agricultural areas. Finally, our model could potentially be used to predict seasonal human-tick exposure risks in France that could contribute to mitigating Lyme borreliosis risks.

\section{Introduction}

In the light of ongoing anthropogenic climate change, redistributions of vector populations and vector-borne diseases have become increasingly concerned as an alarming public health threat ${ }^{1}$. The effects of climate change on the population of Ixodes ricinus ticks (Acari: Ixodidae), the most important arthropod vector species in Europe, have become the topic of interest in this region ${ }^{2}$. The life cycles and key ecological processes of ixodid ticks, such as mortality, development rate, and questing behaviour, are sensitive to weather conditions ${ }^{3,4}$. Therefore, variations in meteorological conditions contribute to the regulation of the dynamics of tick abundance, phenology of questing activity, and eventually, human-tick exposure risks throughout the year. However, the direct impacts of climate change on tick population dynamics related to abiotic factors, such as temperature and relative humidity, are not always straightforward. Rising temperatures could promote the probability of questing activity and interstadial developmental rate; however, ticks may also face a higher mortality risk at the same time ${ }^{4}$. Meanwhile, relative humidity influences the water regulation of ticks, affecting their questing behaviour and survival ${ }^{5-7}$. Furthermore, climate change could also pose indirect effects on tick populations through biotic factors, such as habitats ${ }^{4}$ and host populations (both density and behaviours) ${ }^{2,8}$. As a result, climate change has been expected to alter the distribution of tick populations, the activity of questing ticks, and human-tick exposure both geographically (poleward and upslope expansions) ${ }^{9,10}$ and seasonally (altered phenology) ${ }^{11}$.

I. ricinus ticks have wide geographical and climatic ranges spanning all over Europe and some regions in northern Africa and western Asia ${ }^{12}$. Long-term observation of the questing activity of $I$. ricinus nymphs, for both phenology and abundance, has been an important indicator for the exposure risks to ticks and tick-borne diseases in these regions, particularly Lyme borreliosis ${ }^{13-16}$. I. ricinus ticks have been observed to exhibit different phenology (a seasonal variation) of questing activity across their wide range of geo-climatic distributions, such as unimodal or bimodal patterns ${ }^{17}$, which determines the time of year when questing ticks are most or least likely to be encountered. While the abundance (a population size) of ticks in each area reflects the suitability/carrying capacity of the habitats for the populations, both land cover and climatic conditions ${ }^{18}$. Furthermore, when the suitability of the habitat is altered, long-term observations can reveal directional changes in questing activity over several years (inter-annual variation) ${ }^{15}$. To evaluate the effects of climate change on the distribution of tick-borne diseases, it is critical to understand the impacts of environmental factors, both abiotic and biotic, on all levels of tick activity variations over a long period of time across various geographical/climatic ranges.

However, most of the previous studies on the environmental effects on I. ricinus nymph activities in Europe did not capture both the temporal (seasonal and inter-annual) and spatial variations. Some studies focused on short-term observations at multiple sites, allowing for the comparison of abundance estimates but not seasonal and inter-annual variations ${ }^{19-22}$. While the other studies were long-term observations at a few sites, capturing seasonal and inter-annual variations and thus unable to compare with multiple sites ${ }^{13-16}$. Furthermore, the most widely used method for monitoring nymph activity, cloth-dragging sampling, has a low capture rate ${ }^{23}$. Therefore, this method produces a high level of uncertainty in abundance estimates across different environmental conditions and field investigators ${ }^{24}$, which makes comparing results from different observatories difficult.

France is a hotspot for $I$. ricinus and Lyme borreliosis ${ }^{25}$ and has a wide range of geographical and climatic characteristics ${ }^{26}$. An in-depth understanding of the characteristics of questing activity of I ricinus across various geo-climatic areas is still needed to help control Lyme borreliosis in this area. The present study sought to investigate the activity of $I$. ricinus nymphs, both phenology and abundance, across a wide range of climatic region types in France over a long-term observation period. The sampling protocol suggested by a previous study was employed to reduce the uncertainty from the cloth-dragging method ${ }^{24}$. Also, this study aimed to assess the impacts of environmental factors, such as meteorological, bioclimatic, and habitat characteristics on the variations of $I$. ricinus nymph questing activity, which could help better understand the effects of climate change on I. ricinus populations.

\section{Material And Methods}

\subsection{Sampling sites}

Longitudinal observation campaigns for I. ricinus nymph activity were carried out at 11 sampling sites in forest areas from 7 different tick observatories across France. Tick observatories are located at the following French municipal areas, where the coordinates of the centre of each municipal area and the climatic types ${ }^{26}$ are also provided as: 1 ) La Tour de Salvagny (4548'50.6"N 442'53.2"E; Mixed climates); 2) Saint-Genès-Champanelle (4543'23.8"N

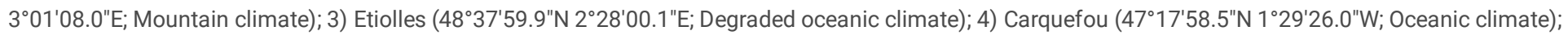
5) Gardouch ( $43^{\circ} 23^{\prime} 25.7^{\prime \prime N} 1^{\circ} 41^{\prime} 02.1^{\prime \prime E}$; South-West Basin climate); 6) Velaine-en-Haye (48² $42^{\prime} 13.4^{\prime \prime} \mathrm{N} 6^{\circ} 01^{\prime} 16.1^{\prime \prime E}$; Semi-continental climate); 7 ) Les Bordes 
(47 48'47.3"N 2²4'01.3"E; Degraded-oceanic climate) (Figure 1). The observation campaigns were carried out from April/June 2014 to May/June 2021 in most observatories, except for Les Bordes, which began in April 2018.

Each tick observatory corresponds to one sampling site except La Tour de Salvagny, Gardouch, and Les Bordes (Table S1). In La Tour de Salvagny, we had to withdraw the observations at the original site (La Tour de Salvagny A) in September 2016 because the site became no longer accessible. In April 2017, we continued our observations at a nearby site, approximately $2 \mathrm{~km}$ apart (La Tour de Salvagny B). In Gardouch, the activity of questing nymphs was observed both inside and outside the enclosed area of an experimental station on roe deer (Capreolus capreolus), referred to as Gardouch Inside and Gardouch Outside, respectively. The estimated population density of roe deer in Gardouch Inside (mean 50 individuals per 100 ha) was higher than Gardouch Outside (estimated by experts as less than 20 individuals per $100 \mathrm{ha}$ ). Furthermore, three sampling sites in Les Bordes, approximately $1.2 \mathrm{~km}$ apart, were referred to as Les Bordes $A, B$, and $C$, respectively. Due to their geographical proximity, the meteorological/climatic factors of different sampling sites from the same observatories were considered identical in further analysis.

Field observation campaigns were planned and carried out by local investigators who had been trained on the sampling protocol. The locations of forests, sampling sites, and passages were chosen where their biotopes are known to be suitable for $I$. ricinus tick populations around each observatory at the time the field observation campaigns started ${ }^{27}$. Besides, the observations were never carried out during the daytime when the weather was highly unfavourable to questing ticks, e.g., heavy rain, snow, or snow cover.

\subsection{Sampling protocol for questing Ixodes ricinus nymphs}

Activity of questing I. ricinus nymphs was observed by a cloth-dragging sampling technique ${ }^{28}$. Within a 1 -km radius, a $1 \mathrm{~m} \times 1 \mathrm{~m}$ white cloth was dragged over 10 observation units of $10 \mathrm{~m}$ short-grass vegetative forest floors, called transects. For each transect, a repeated removal sampling design was used 24 . The cloth-dragging sampling process was successively repeated three times per sampling. Nymphs found the white cloth were removed and collected in a vial for morphological identification ${ }^{29}$ by the same acarologists at the corresponding laboratories. As a result, the questing nymph activity of each sampling site was monitored as a total number of confirmed $l$. ricinus nymphs collected from three repeated sampling on 10 transects, equivalent to a surface area of 100 m². This measure was considered as a proxy for tick abundance on the day of sampling. The same transects were repeatedly sampled throughout the study period at approximately 1-month intervals.

\subsection{Environmental data}

We tested 28 environmental variables to explain the observed I. ricinus nymph activity (Table 1). These variables could be categorized as: 1) Daytime duration and meteorological variables (time-dependent, 9 variables); 2) Land cover, topography, and bioclimatic variables (time-independent, 19 variables). 
Table 1

Environmental variables (meteorological, land cover, topography, and bioclimatic variables) used to explain the abundance of $I$. ricinus ticks in regression analysis.

\begin{tabular}{|c|c|c|c|}
\hline Type & Group & Variable & Description \\
\hline \multirow[t]{9}{*}{ Meteorological } & \multirow[t]{4}{*}{ Temperature } & $T_{M}^{0: 1}$ & $\begin{array}{l}\text { One-month average temperature; average temperature from } 30 \text { preceding days to } \\
\text { the sampling day }\left({ }^{\circ} \mathrm{C}\right)\end{array}$ \\
\hline & & $T_{M}^{3: 6}$ & $\begin{array}{l}\text { Previous season average temperature; average mean temperature of preceding } 3 \\
\text { to } 6 \text { months }\left({ }^{\circ} \mathrm{C}\right)\end{array}$ \\
\hline & & $T_{M}^{0: 6}$ & $\begin{array}{l}\text { Half-year average mean temperature; between } 6 \text { preceding months to the } \\
\text { sampling day }\left({ }^{\circ} \mathrm{C}\right)\end{array}$ \\
\hline & & $T_{M}^{0: 12}$ & $\begin{array}{l}\text { Average annual mean temperature; between } 12 \text { preceding months to the sampling } \\
\text { day }\left({ }^{\circ} \mathrm{C}\right)\end{array}$ \\
\hline & \multirow[t]{4}{*}{$\begin{array}{l}\text { Relative } \\
\text { humidity }\end{array}$} & $U_{N}^{0: 1}$ & $\begin{array}{l}\text { One-month minimum relative humidity; average value from } 30 \text { preceding days to } \\
\text { the sampling day (\%) }\end{array}$ \\
\hline & & $U_{N}^{3: 6}$ & Previous season minimum relative humidity of preceding 3 to 6 months (\%) \\
\hline & & $U_{N}^{0: 6}$ & $\begin{array}{l}\text { Half-year average minimum relative humidity; between } 6 \text { preceding months to the } \\
\text { sampling day }(\%)\end{array}$ \\
\hline & & $U_{N}^{0: 12}$ & $\begin{array}{l}\text { Average annual minimum relative humidity; between } 12 \text { preceding months to the } \\
\text { sampling day (\%) }\end{array}$ \\
\hline & Daytime & daytime & Daytime duration (h) \\
\hline \multirow{19}{*}{$\begin{array}{l}\text { Land cover, topography, and } \\
\text { bioclimate }^{\text {a }}\end{array}$} & \multirow[t]{8}{*}{ Topography } & $\operatorname{mean}_{e l v}$ & Mean elevation $(\mathrm{m})$ \\
\hline & & $s d_{e l v}$ & Standard deviation of elevation (m) \\
\hline & & $p_{\text {flat }}$ & Proportion of flat area; slope $\leq 2.5 \%$ \\
\hline & & $p_{\text {north }}$ & Proportion of non-flat area facing north; aspect $<45^{\circ}$ or $\geq 315^{\circ}$ \\
\hline & & $p_{\text {east }}$ & Proportion of non-flat area facing east; $45^{\circ} \leq$ aspect $<135^{\circ}$ \\
\hline & & $p_{\text {west }}$ & Proportion of non-flat area facing west; $135^{\circ} \leq$ aspect $<225^{\circ}$ \\
\hline & & $p_{\text {south }}$ & Proportion of non-flat area facing south; $225^{\circ} \leq$ aspect $<315^{\circ}$ \\
\hline & & Catchment & Catchment area \\
\hline & Bioclimate & $B I O 1_{\text {temp }}$ & Annual mean temperature $\left({ }^{\circ} \mathrm{C}\right)$ \\
\hline & & $B I O 2_{\text {diur }}$ & Mean diurnal range $\left({ }^{\circ} \mathrm{C}\right)$ \\
\hline & & BIO5 maxTemp & Maximum temperature of the hottest month $\left({ }^{\circ} \mathrm{C}\right)$ \\
\hline & & $B I O 12_{\text {prec }}$ & Annual precipitation (mm) \\
\hline & Land cover & $H_{C L C 1}$ & Shannon's diversity index for level-1 CLC types \\
\hline & & $H_{C L C 2}$ & Shannon's diversity index for level-2 CLC types \\
\hline & & $H_{\text {Forest }}$ & Shannon's diversity index for forest types \\
\hline & & $p_{\text {Forest }}$ & Percentage of forest-covering area (\%) \\
\hline & & $n_{\text {Forest }}$ & Number of forest patches \\
\hline & & $E D_{\text {Forest }}$ & Forest edge density $\left(\mathrm{m} / \mathrm{km}^{2}\right)$ \\
\hline & Soil & $p H_{\text {soil }}$ & Soil pH \\
\hline
\end{tabular}

\subsubsection{Daytime duration and meteorological variables}

Daytime duration (daytime) from January 2013 to June 2021 at each sampling site was obtained from the corresponding latitude using geosphere package $^{30}$. Hourly meteorological data (2-m temperature and relative humidity) were recorded locally at each forest. Subsequently, daily mean, minimum, and 
maximum values of temperature $\left(T_{M}, T_{N^{\prime}}\right.$ and $T_{X^{\prime}}$ in $\left.{ }^{\circ} \mathrm{C}\right)$ and relative humidity $\left(U_{M^{\prime}}, U_{N^{\prime}}\right.$ and $U_{X^{\prime}}$ in \%) were derived from these hourly records.

Missing values found on these local daily-level variables were imputed by the random forest algorithm in mice package ${ }^{31}$. External daily meteorological data, i.e., daily average temperature and relative humidity, derived from neighbouring weather stations (Météo-France or INRAE), as well as month and year information, were used as auxiliary variables (Table S2). As a result, the imputation process creates a total of 500 iterated values for each variable. The median values of 500 imputations were used to replace the missing values.

The imputed daily meteorological data were subsequently used to calculate the averaged values in different lagged time intervals for further analysis, called interval-average variables ${ }^{14}$. The interval-average variables were generated to reduce the uncertainty that might arise during the imputation process and to capture the cumulative effects of the meteorological variables, which were mean temperature $T_{M}$ and minimum relative humidity $U_{N}$. The mean temperature was selected to represent the effects of overall temperature on the tick population, whereas the minimum relative humidity was chosen to represent the effects of desiccation stress. The interval-average variables were defined as the average values of a meteorological variable $M \in\left\{T_{M}, U_{N}\right\}$ during a period between $t_{1}$ to $t_{2}$ month(s) before the sampling, denoted as $M_{1}^{t_{1}}: t_{2}$, where one month consists of 28 days. For instance, $U_{N}^{0: 6}$ represents an average of the minimum daily relative humidity between 0 to 6 months ( 0 to 168 days) before the day of sampling.

Here, we hypothesized that interval-average meteorological conditions influence the dynamics of observed nymph activity at different time lags in different manners. Short-term lags may have an impact on immediate responses, such as the probability of questing. At the same time, long-term lags may influence the dynamics of nymph abundance, which is associated with development and survival rates. Therefore, we explored the impact of each meteorological variable at following time lags on the observed nymphs activity in subsequent regression analysis: 1) One-month average condition, $M^{0: 1}$; 2 ) Previous-season average condition, $M^{3: 6}$; 3) Half-year average condition, $M^{0: 6}$;4) Annual average condition, $M^{0: 12}$.

In addition to the interval-average variables, monthly and seasonal average values of mean temperature and minimum relative humidity during the observation period were also calculated to describe the characteristics of meteorological conditions of each sampling site.

\subsubsection{Land cover, topography, and bioclimatic variables}

We obtained land cover, topography, and bioclimatic data from a 1-km radius buffer area around the center of each sampling site to capture habitat characteristics across all 10 transects. All the variables were handled and obtained by using QGIS version 3.8.0 ${ }^{32}$. The digital elevation model (DEM) data derived from the Shuttle Radar Topography Mission (SRTM) database ${ }^{33}$ was used to describe the topographic features of sampling sites, which included the

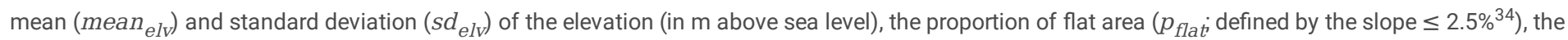
proportion of area facing north $\left(p_{\text {north }}\right)$, east $\left(p_{\text {east }}\right)$, west $\left(p_{\text {west }}\right)$, and south $\left(p_{\text {south }}\right)$, and the catchment area (catchment) as a proxy variable for moisture. Bioclimatic variables for each site (historical average conditions during 1970 to 2000 ) were derived from the WorldClim database ${ }^{35}$, including the annual mean temperature $\left(B I O 1_{T e m p}\right.$; in $\left.{ }^{\circ} \mathrm{C}\right)$, the mean diurnal range $\left(B I O 2_{\text {Diur }}\right.$ in $\left.{ }^{\circ} \mathrm{C}\right)$, the maximum temperature of the warmest month $\left(B I O 5_{\text {maxTemp }}\right.$ in $\left.{ }^{\circ} \mathrm{C}\right)$, and the annual precipitation $\left(B I O 12_{P r e c}\right.$ in $\mathrm{mm}$ ). The land cover features of each sampling site were described using the CORINE Land Cover (CLC) $2018^{36}$, while the characteristics of forests were explained by the BD forêt version 2 data ${ }^{37}$. The forest fragmentation was characterized by the percentage of forest-covering area $\left(p_{\text {Forest }}\right)$, the forest edge density $\left(E D_{\text {Forest }}\right.$ in $\left.\mathrm{m} / \mathrm{km}^{2}\right)$, and the number of forest patches $\left(n_{\text {Forest }}\right)$. While the diversities of the land cover types (level- 1 and level-2 CLC) and the forest types were calculated by using the Shannon's diversity index ${ }^{38}(H)$ as $H=\sum_{i=1}^{S} p_{i} \ln p_{i}$, where $S$ is the total number of land cover/forest types and $p_{i}$ is the proportion of land cover/forest type $i$ within the 1-km radius buffer area. The Shannon's diversity index for level-1 CLC, level-2 $\mathrm{CLC}$, and forest types were denoted as $H_{C L C 1}, H_{C L C 2}$, and $H_{F o r e s t}$ respectively. Finally, the soil pH data $\left(p H_{\text {soil }}\right)$ was retrieved from the European Soil Data Centre (ESDC) database ${ }^{39}$.

\subsection{Statistical analysis}

All the statistical analyses were carried out using the programming language R version $3.6 .0^{40}$. The phenological pattern of nymph activity of each site was assessed using normalized monthly median nymph counts, where 0 and 1 indicated minimum and maximum values, respectively. Subsequently, the phenological patterns were descriptively classified using the following criteria: 1 ) The season which the peaks of activity arrive; 2 ) Evidence of reduced activity during winter (November to January); 3) The number of activity waves in a year, whether the pattern is unimodal or bimodal. Further, the directional changes in the maximum nymph counts were tested using a Spearman's rank correlation coefficient, a $p$-value $<0.05$ was considered significant.

The effects of environmental variables (meteorological, land cover, topographical and bioclimatic variables) on the abundance of $I$. ricinus nymphs, were evaluated by a multivariate mixed-effects negative binomial regression, using the $g / m m T M B$ package ${ }^{41}$. Recalled that the negative binomial distribution is a generalized form of the Poisson distribution with an additional shape parameter $\theta$ that allows the variance to be independent to the mean $\mu$. The number of $I$. ricinus nymphs per $100 \mathrm{~m}^{2}$ was considered the response variable, and the sampling site served as the random effects for intercepts as displayed in (1):

$$
\begin{aligned}
& N_{i} \tilde{N} \operatorname{NegBinom}\left(\mu_{i}, \theta\right) \\
& \ln \mu_{i}=\alpha_{0}+\alpha_{i}+X_{i} \beta
\end{aligned}
$$

Where $N_{i}$ denoted nymph counts per $100 \mathrm{~m}^{2}$ of site $i, \mu_{i}$ and $\theta$ represented mean of site $i$ and the shape parameter of the negative binomial distribution, respectively. $\alpha_{0}$ was an intercept of the regression model, while $\alpha_{i}$ was the random intercept of site $i$. Finally, $X_{i}$ and $\beta$ denoted a covariate vector of site $i$ and a vector of regression coefficients for fixed effects, respectively. 
The multicollinearity among all environmental variables was evaluated using Pearson's correlation coefficient $r$. Highly correlated variables, with $|r| \geq 0.6$, were not included in the same model. The principal component analysis (PCA) was used to reduce the dimensions of multiple highly correlated Land cover, topography, and bioclimatic variables, using FactoMine $R^{42}$ and factoextra ${ }^{43}$ packages. To reduce the number of variables considered in the regression analysis, the coordinates of individual sampling sites on the PCA dimensions were subsequently explored as explanatory variables. Non-linearity and interaction effects of the fixed effects were also investigated.

Multivariable models were explored by both forward and backward selection of significant variables decreasing the Akaike information criterion (AIC). Variations of the data explained by fixed effects were monitored by a pseudo- $\mathrm{R}^{2}$ statistic using the MuMln package ${ }^{44}$. Residuals of the models were evaluated using the DHARMa package ${ }^{45,46}$. The performance of the best-fitted model was assessed by a resampling method. Briefly, $50 \%$ of the original dataset was randomly sampled to fit with the best model for 500 iterations, referred to as resampling models. The distributions of regression coefficients across 500 resampling models were compared against those of the model with the original dataset, called the complete model. Additionally, the coverage probability (CP) of each explanatory variable, defined as the percentage of resampling models that produced regression coefficients that were significantly different from zero $(p<0.05)$, were also calculated. The CP index is a measure of how robust each variable is to explain observed data. Finally, the effects of each environmental variable were predicted using the effects package ${ }^{47}$.

\section{Results}

\subsection{Characteristics of sampling sites}

During 2014 to 2021, the activity of questing I. ricinus nymphs was observed from 11 sample sites at 7 tick observatories in France. The characteristics of each sampling site, i.e., meteorological, land cover, topography, and bioclimatic features, appeared to be highly correlated (Figure S1). According to the meteorological conditions (Figures 2, S2, S3A, and S3B), the characteristics of tick observatories can be classified as: 1) cold average temperature with the average winter temperature $<2.5^{\circ} \mathrm{C}$ (Saint-Genès-Champanelle and Velaine-en-Haye); 2 ) warm average temperature with average winter temperature $\sim 7^{\circ} \mathrm{C}$ and high summer humidity with average minimum relative humidity in summer $>60 \%$ (Gardouch and Carquefou); 3 ) intermediate average temperature with average winter temperature between 4 to $6^{\circ} \mathrm{C}$ and low summer humidity with average minimum relative humidity in summer $<55 \%$ (La Tour de Salvagny, and Etiolles).

The land cover, topography, and bioclimatic characteristics of each sampling site were described in Tables S3 to S5, respectively. The first two dimensions of the principal component analysis (PCA) explained $70.3 \%$ of the variation in the land cover, topography, and bioclimatic variables (Figures $3 \mathrm{~A}$ and S4). The first dimension differentiated each sampling site predominantly based on forest and land cover characteristics, in which the first 4 contributions were the number of forest patches $n_{\text {Forest }}$ percentage of forest-covering area $p_{\text {Forest }}$ Shannon's diversity index for forest types $H_{\text {Forest }}$ and Shannon's diversity index for level-2 CORINE Land Cover (CLC) types $H_{C L C 2}$, respectively (Figures $3 \mathrm{~A}$ and S4). The Shannon's diversity index for forest types $H_{F o r e s t}$ was found to be negatively correlated with the Shannon's diversity index for the CLC types, $H_{C L C 1}$ and $H_{C L C 2}$, (Figure S1). The sampling sites in La Tour de Salvagny A, La Tour de Salvagny B, Gardouch Inside and External were relatively high fragmented forests, less percentage of forest-covering areas, more diverse in the CORINE Land Cover types, and less diverse in the forest types. While the sampling sites in Saint-Genès-Champanelle, Les Bordes and Etiolles were covered by a high percentage of forest areas with less forest fragmentation and high diversity in forest types.

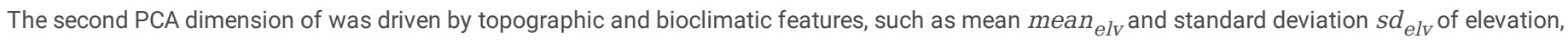
proportion of non-flat area facing north $p_{\text {north }}$, annual precipitation $B I O 12_{\text {prec }}$, and annual mean temperature $B I O 1_{\text {Temp }}$ (Figures $3 \mathrm{~A}$ and S4). The sampling site in Saint-Genès-Champanelle was located at a high uneven elevation above the sea level (mountainous) with higher annual precipitation and lower annual temperature compared to all other sampling sites. While sampling sites of Les Bordes and Etiolles were located at flat areas with the lowest annual precipitation. The coordinates for each sampling site on the first and second dimensions on the PCA plot (Figure 3B) were used to describe land cover, topography, and bioclimatic characteristics in subsequent regression analysis, denoted as Dim1 and Dim2, respectively. In addition, soil in the forest of Les Bordes appeared to be acidic, with an estimated pH of 4 (Table S3).

\subsection{Activity of Ixodes ricinus nymphs}

During the observation period, 631 campaigns were carried out, yielding a total of 22,912 I. ricinus nymphs (Table S1). The baseline level of nymph counts was highest in Gardouch Inside, La Tour de Salvagny B, and Carquefou, while it was the lowest in Saint-Genès-Champanelle, La Tour de Salvagny A, and Les Bordes A to C (Figures 4 and S3C). The normalized nymph counts revealed three phenological patterns of questing nymph activity observed among the 11 sampling sites (Figures 5 and S3D): 1) Pattern 1, a unimodal pattern with a relatively long peak activity beginning in late spring, reaching its maximum in summer and fading out in autumn, with no or very low activity in winter (Saint-Genès-Champanelle, Velaine-en-Haye, and La Tour de Salvagny B); 2) Pattern 2: a bimodal pattern with an earlier nymph activity reaching its peak in spring (the first peak), fading out in summer, reappearing in autumn (the second peak), and fading out again in winter (Les Bordes A to C, La Tour de Salvagny A, and Etiolles); 3) Pattern C: a unimodal pattern with moderate nymph activity throughout autumn and winter, reaching its peak earlier in spring, and fading out in summer (Carquefou, Gardouch Inside, and Gardouch Outside). Interestingly, questing nymphs have also been observed during winter in most sites. In addition, a decreasing trend in annual maximum nymph counts was observed more evidently in Gardouch Outside (Spearman's rank correlation coefficient $=-0.8982$; $p$-value $<0.05$ ), while no apparent directional change was observed in other sites (Figures 4 and S5).

\subsection{Environmental impacts on nymphs activity}

Several mixed-effects negative binomial regression models were evaluated to explain impacts of environmental factors on observed $I$. ricinus nymph counts. The best-fitted model was selected by the AIC value, while other model characteristics were compared by dispersion parameter, variance of the random 
intercepts, and pseudo- $\mathrm{R}^{2}$ statistics (Table 2). Fixed effects in Model 5, predominantly meteorological variables, explained $65.1 \%$ of the total variance of nymph counts.

Table 2

The Akaike information criterion (AIC), dispersion parameter of the negative binomial regression, and the variance of the intercepts when sampling sit $\epsilon$

\begin{tabular}{lll} 
Model & Description & AlC \\
\hline 0 & Null & 5447 \\
1 & $\left(T_{M}^{0: 1}\right)^{3}+\left(T_{M}^{0: 1}\right)^{2}+T_{M}^{0: 1}$ & 5272 \\
2 & $\left(T_{M}^{0: 1}\right)^{3}+\left(T_{M}^{0: 1}\right)^{2}+T_{M}^{0: 1} * B I O 1_{\text {temp }}$ & 5256 \\
3 & $\left(T_{M}^{0: 1}\right)^{3}+\left(T_{M}^{0: 1}\right)^{2}+T_{M}^{0: 1} * B I O 1_{\text {temp }}+\left(T_{M}^{3: 6}\right)^{3}+\left(T_{M}^{3: 6}\right)^{2}+T_{M}^{3: 6}$ & 4858 \\
4 & $\left(T_{M}^{0: 1}\right)^{3}+\left(T_{M}^{0: 1}\right)^{2}+T_{M}^{0: 1} * B I O 1_{t e m p}+\left(T_{M}^{3: 6}\right)^{3}+\left(T_{M}^{3: 6}\right)^{2}+T_{M}^{3: 6}+\left(U_{N}^{0: 6}\right)^{3}+\left(U_{N}^{0: 6}\right)^{2}+U_{N}^{0: 6}$ \\
5 & $\left(T_{M}^{0: 1}\right)^{3}+\left(T_{M}^{0: 1}\right)^{2}+T_{M}^{0: 1} * B I O 1_{t e m p}+\left(T_{M}^{3: 6}\right)^{3}+\left(T_{M}^{3: 6}\right)^{2}+T_{M}^{3: 6}+\left(U_{N}^{0: 6}\right)^{3}+\left(U_{N}^{0: 6}\right)^{2}+U_{N}^{0: 6}+(\operatorname{Dim} 1)^{3}+(\operatorname{Dim} 1)^{2}+\operatorname{Dim1} \quad 4811$
\end{tabular}

Asterisks indicated the interaction terms between 2 variables.

Model diagnostics showed no indication of lack of fit (Kolmogorov-Smirnov test: $p$-value $=0.2067)$, under- or over-dispersion in the residuals $(p$-value $=0.08)$, or residual outliers ( $p$-value $=1$ ) (Figure S6). The strength of the best-fitted model was assessed by resampling half of the data to fit with this model. The regression coefficients yielded from 500 resampling models were similar to those of the complete model with mostly high coverage probability (Figure $\mathrm{S} 7$ and Table S6).

The best-fitted model (Model 5) suggested that phenology of $I$. ricinus nymphs non-linearly responded to meteorological factors, such as one-month average temperature $T_{M}^{0: 1}$, previous season temperature $T_{M}^{3: 6}$, and half-year average minimum relative humidity $U_{N}^{0: 6}$. The optimal condition for one-month average temperature $T_{M}^{0: 1}$ on nymph counts varied depending on the annual average temperature $B I O_{T e m p}$ (Figure $6 \mathrm{~A}$ ). Nymph counts were expected to be higher when the previous season was cold (Figure 6B) and when the humidity was high during the past 6 months (Figure 6C). It should be noted that because the daytime duration was highly correlated with several meteorological variables, such as one-month average temperature, previous season temperature, and onemonth average minimum relative humidity (Figure S1), it was excluded from the best-fitted model.

The Dimension-1 PCA coordinates Dim1, representing the forest and land cover characteristics of different sampling sites, markedly reduced the variance of random intercepts from 1.0004 in Model 4 to 0.4224 in Model 5 (Table 2). Thus, the forest and land cover characteristics in Model 5 gave a significant explanation of the baseline nymph count levels. The landscape that supports more baseline nymph counts was suggested to have a moderate percentage of forest-covering areas $\{p\}_{-}\{$Forest $\}$, number of forest patches $\{n\}_{-}\{$Forest $\}$, and Shannon's diversity index for level-1 (\{H\}_\{CLC1 $\left.\}\right)$and level-2 CORINE Land Cover types $\left(\{\mathrm{H}\}_{-}\{\mathrm{CLC} 2\}\right)$ (Figure 6D).

Finally, the prediction from the best-fitted model replicated well the phenological patterns of observed I. ricinus nymphs (Figures 5 and S8), particularly sampling sites with more observations, i.e., Saint-Genès-Champanelle, Velaine-en-Haye, Etiolles, Carquefou, Gardouch Inside, and Gardouch Outside. However, the autumn peaks of the phenological Pattern 2 (Figure 5) and the interannual variations of the nymph counts (Figure S8) remain imperfectly predicted by the model using meteorological variables.

\section{Discussion}

The variations in tick activity across space and time can be classified into 4 levels: 1) Baseline abundance variation; 2) Sub-daily variation; 3) Seasonal variation; 4) Inter-annual variation. The baseline abundance reflects the suitability/carrying capacity of the habitats for the populations, both land cover and climatic conditions ${ }^{18}$. The sub-daily variation arises from the immediate responses of questing ticks to the environment, such as temperature, relative humidity, or photoperiod ${ }^{48}$, reflecting the instantaneous probability of questing. While seasonal and inter-annual variation reflects the long-term cumulative results of the questing behaviour as well as reproduction, development, and mortality rates on the tick population ${ }^{3}$. However, previous studies on the effects of the environment on I. ricinus nymph activities in Europe did not capture all the aforementioned levels of variation. They largely focused on either a short-term period for multiple sites ${ }^{19-22}$ or a long-term period for a few areas ${ }^{13-16}$. The present study attempted to explore the baseline abundance, seasonal, and interannual variations of $I$. ricinus nymph activity by expanding the observation across a wide range of geographical/climatic areas over a long period, involving a total of 11 sampling sites from 7 tick observatories in France over 8 years. With the repeated removal sampling design, we controlled the uncertainty on the proxy measure of tick abundance (nymph counts per $100 \mathrm{~m}^{2}$ ) that arises from the variability of sampling rate across different sites and times ${ }^{24,49}$.

Furthermore, all transects were covered with low vegetations, which were shown to maximize sampling rates compared to other types of vegetative floors ${ }^{24}$, resulting in higher accuracy in estimating the proxy of tick abundance. To avoid the uncertainty caused by the variations of the environment within a sampling site, we repeated tick sampling from the same transects throughout the observation period. Furthermore, we strived to minimize the interference of tick 
populations and their environment during the long-term observation period by using a one-month sampling interval. As all of the transects were open areas, ticks were free to relocate in and out of the transects, either directly or through hosts, and compensate for the monthly removals of tick populations. Nevertheless, the sub-daily variations in questing behaviour or immediate response to meteorological conditions among nymphs from different regions were not captured by this study design.

We observed the phenological patterns of nymph activity tended to follow the characteristics of meteorological conditions: 1) Pattern 1, a unimodal pattern with a broad summer peak and a winter pause in colder climates (Saint-Genès-Champanelle, and Velaine-en-Haye); 2) Pattern 2, a bimodal pattern with spring and autumn peaks in intermediate climates with dry summer (Les Bordes A to C, and Etiolles); 3) Pattern 3, a unimodal pattern with an early spring peak without a winter pause in warm and humid climates (Carquefou and Gardouch). However, despite the phenological patterns 1 and 3 being clearly distinct, we found that the existence of the autumn peaks in pattern 2 was ambiguous for the following reasons: 1) Most sites with phenological pattern 2 had a low baseline abundance level. One additional nymph count due to variability of the sampling could lead to a significant false signal for the autumn activity; 2 ) Compared to other patterns, tick activity at most sites with phenological pattern 2 was observed for a shorter period (a smaller sample size). A longer observation period is required to confirm the presence of bimodal patterns at these sites. Furthermore, we observed different phenological patterns at La Tour de Salvagny A and B, despite these two sites being approximately 2-km apart. The heterogeneity of the phenological patterns could have arisen from the following reasons: 1) The phenological pattern 2 observed from a short-term period at La Tour de Salvagny A was ambiguous, as previously discussed; 2 ) Different landscapes and host densities influenced tick population dynamics and apparent tick activities differently.

The overall phenology patterns observed in our study followed a climatic gradient previously reported on I. ricinus adults across northern Africa to eastern Europe, with a unimodal pattern with a summer peak and a winter pause in freezing climates (Karelia, Russia), a bimodal pattern with spring and autumn peaks in intermediate climates (European Russia's temperate zone), and a unimodal pattern with a late winter peak in warm climates (Algeria) ${ }^{17}$. Also, a similar phenology trend observed in one mountain region in Switzerland was reported to follow an elevation gradient where the spring-autumn bimodal phenology shifted to a late-spring unimodal pattern at a higher elevation, presumably due to a temperature gradient ${ }^{16}$. Therefore, it is conceivable to hypothesize that a gradually warming climate will result in the following phenological changes to I. ricinus: 1 ) At colder climates, the activity peaks could have shifted towards late-winter or early-spring; 2) At warmer and drier climates, the habitats would no longer support the physiological needs of $I$. ricinus. However, a spring-autumn bimodal phenology was also observed in a freezing climate in Finland ${ }^{50}$, where the population genetics structure was completely different from that of $I$. ricinus in western Europe ${ }^{51}$. This suggested that $I$. ricinus from different climatic regions could have adapted/evolved to questing for a host at different temperature thresholds ${ }^{52}$ and responded differently to climate change. Furthermore, our findings indicated that describing phenological patterns solely based on their shape, such as unimodal or bimodal, was insufficient. Rather, the timing of the phenology peak and the winter traits should also be addressed. As a consequence, in order to better understand the relationship between climatic gradient and phenological patterns, we recommend longitudinal studies conducted over large geographic areas to report the phenological pattern of each sampling location separately. Moreover, determining the age of nymphs through fat content analysis has been demonstrated to guide formulating hypotheses about the mechanisms for the population dynamics of each phenological pattern ${ }^{16}$.

As the computation for cumulated nymph counts using areas under the density curve ${ }^{15}$ requires strictly regular sampling intervals throughout the study period, we used annual maximum nymph counts as a proxy to explore inter-annual variations in questing nymph activity. Directional changes in the annual maximum nymph counts were observed only in Gardouch Outside but not Gardouch Inside, despite being located in the same area. We hypothesized that it could have occurred as a result of 1) A possible decrease in roe deer population outside of the experimental station, while the number of roe deer was always maintained vastly high inside the experimental station; or 2) The periods of heatwaves that impacted this area in summer 2019 and summer 2020 affected the tick survival, while the high host density in Gardouch Inside compensated the surge in tick mortality. Furthermore, a recent study suggested that the inter-annual fluctuation of nymph abundance could be explained by the level of tree seed production, and thus the abundance level of small mammal hosts, in previous years ${ }^{53}$. However, retrospective data on seed production were not available for all of our sampling sites during the study period, which precluded us from exploring this hypothesis in this study.

The regression analysis suggested that high nymph counts were non-linearly associated with different interval-average variables, including lower previous season temperature $\{T\}_{-}\{M\}^{\wedge}\{3: 6\}$, higher half-year average minimum relative humidity $\{U\}_{-}\{N\}^{\wedge}\{0: 6\}$, and a range of optimal one-month average temperature $\{T\}_{-}\{M\}^{\wedge}\{0: 1\}$. As the number of nymphs collected in each sampling was a product of total population size of nymphs at the time of sampling (true abundance), the proportion of nymphs questing for a host, and the sampling rates, we hypothesized that the meteorological conditions influenced each of these unobserved parameters at different time lags. The population size is determined by the cumulative effect of past meteorological conditions, either through mortality rate or larva-to-nymph developmental rate. While the proportion of questing nymphs tended to respond to short-term fluctuation of the weather conditions ${ }^{54}$. A longitudinal observation on one site in Germany found similar effects of interval-average variables that explain the phenological pattern and inter-annual variation of $I$. ricinus activity ${ }^{14}$, which were current temperature $\{T\}_{-}\{M\}^{\wedge}\{0: 0\}$, four-to-six previous months average temperature $\{T\}_{-}\{M\}^{\wedge}\{4: 6\}$, and one-month average relative humidity $\{U\}_{-}\{M\}^{\wedge}\{0: 1\}$. Furthermore, the best-fitted model also showed a significant interaction between the onemonth average temperature and a bioclimatic variable (average annual temperature $\{\mathrm{BIO}\}_{-}\{\mathrm{Temp}\}$ ). This result indicated that although $I$. ricinus from colder climates start questing at lower temperature thresholds ${ }^{52}$, their activity arrives at its peak at higher temperatures (in summer; temperature $\sim 14$ to $16^{\circ} \mathrm{C}$ ). While tick activity in warmer climates peaks at lower temperatures (in spring; temperature $\sim 11$ to $14^{\circ} \mathrm{C}$ ). Presumably, the population size of active nymphs in cold climates is unlikely to reach its peak during a colder spring due to developmental or behavioural diapause. In addition, photoperiod has also been proposed to regulate both behavioural and developmental diapause of ixodid ticks ${ }^{55}$; therefore, the exclusion of daytime duration from the best-fitted model, which was highly correlated with several meteorological variables, does not rule out the effects of photoperiod on tick activity dynamics.

The regression model also suggested that the baseline abundance level was associated with land cover characteristics. Sampling sites with a transition between moderately fragmented forest and non-forest areas, such as grassland or agricultural areas, support higher baseline nymph abundance (La Tour de 
Salvagny B, Gardouch Inside, Gardouch Outside, and Carquefou; \{p\}_\{Forest $~ 17$ to 52\%). While landscapes with a high proportion of forest covers $\left(\{p\} \_\{\text {Forest }\}>90 \%\right.$ ) tended to have intermediate (Velaine-en-Haye and Etiolles) or low (Les Bordes A to C, and Saint-Genès-Champanelle) baseline abundance level. These findings are consistent with previous studies ${ }^{56-58}$, indicating that forest fragmentation created transitional forest areas known as ecotones, which attract several mammal hosts ${ }^{21}$ and lead to a higher tick abundance. In addition, it has been suggested that forest fragmentation increases not only tick abundance but also the prevalence of pathogen-infected ticks ${ }^{61}$ and the risks of human-tick exposure ${ }^{62}$, which may lead to a higher incidence of tick-borne diseases. We also observed markedly low baseline I. ricinus abundance in the highly fragmented forest with a low proportion of forest-covering area (La Tour de Salvagny $A ;\{p\}_{-}\{$Forest $\left.\}=6.5 \%\right)$, possibly due to the lack of large foraging hosts in such a landscape ${ }^{63}$. Furthermore, we found a remarkably low baseline abundance in all three sampling sites in Les Bordes, which could not be fully explained biologically by our available environmental factors. This could be explained by the unsuitable conditions of Les Bordes forest, where superimposed layers of clay and sand lead to a temporary perched water table in winter, and the low soil water storage capacity leads to arid soil conditions in the upper parts of the soil profile during summer months with low rainfall. Other additional factors could also contribute to explain the low tick abundance at Les Bordes site such as host abundance, competition, or predation of a forest with such high biodiversity.

Desirable model diagnostic results and repeated resampling models using half of the original data produced similar estimate values over 500 iterations, indicating that all explanatory variables in the best-fitted model are robust. Model predictions also successfully predicted baseline abundance, phenology patterns, and inter-annual variations of $I$. ricinus nymph activity. However, the prediction from the one-month average model still imperfectly captured the autumn peak in the phenology Pattern 2, where the sampling sites with this pattern had both fewer observations and lower abundance. This has brought us to the following inconclusive explanations: 1) The model failed to replicate the apparent autumn activity peak more clearly; 2) The apparent autumn peak was observed at random, and one additional nymph collected could generate a false signal when the sample size and baseline abundance were both small. As a result, it is envisioned that a more extended observation period and more sampling sites encompassing all phenological patterns should be implemented. Finally, although the regression analysis has been primarily used to find robust associations of environmental factors and help formulate ecological hypotheses on tick activity, it is considered a phenomenological model that does not fully explain the mechanisms of the observed phenomena ${ }^{3}$. In light of growing concerns about the impact of climate change on tick-borne diseases, particularly Lyme borreliosis, the mechanistic modelling framework for $I$. ricinus population dynamics is still required to investigate these ecological hypotheses.

\section{Conclusions}

The study design in this study allowed us to longitudinally monitor the questing I. ricinus nymph activity, which is comparable across multiple tick observatories. Two distinct phenological patterns were identified in colder climates (a unimodal pattern with a summer peak and complete winter pause) and warmer climates (a unimodal pattern with an early-spring peak without winter pause). While a longer observation period is still required to confirm the presence of a spring-autumn bimodal phenological pattern in intermediate climates. Furthermore, the regression analysis revealed that phenological patterns and inter-annual variations in questing activity were associated with meteorological variables at different lag times. Our results also supported the notion that moderate forest fragmentation promotes higher nymph abundance. Our findings can guide formulating ecological hypotheses about the effects of climate change on the distribution, abundance, and phenology of this tick species, which can then be assessed using a mechanistic population dynamics model. Finally, the phenological patterns of $I$. ricinus activity predicted by our model could potentially be employed to develop tick-borne disease prevention tools, such as developing a seasonally dynamic human-tick exposure risk map, which could help to reduce Lyme borreliosis cases in France.

\section{Declarations}

\section{Acknowledgement}

Most tick observatories were supported by the CC-EID and Climatick projects: "Adaptation of Agriculture and Forests to Climate Change" metaprogramme of the French National Research Institute for Agriculture, Food and Environment (INRAE). The observatory of Les Bordes was installed and equipped by the Centre Val-de-Loire region, the Loiret and the French National Forest Office. The Les Bordes site belongs to the French national research infrastructure, ANAEEF (http://www.anaee-france.fr/fr/), and is included in the SOERE TEMPO (https://tempo.pheno.fr/). The Les Bordes site is also part of the framework of the ZAL (LTSER Zone Atelier Loire) and the GIS Coop network (https://www6.inra.fr/giscoop/), which is supported by the French Ministry for Agriculture and Food. This study was partially funded by EU grant 874850 MOOD and is catalogued as MOOD 000. The contents of this publication are the sole responsibility of the authors and don't necessarily reflect the views of the European Commission. Also, PW is grateful for a grant from the Association Nationale de la Recherche et de la Technologie, bourse CIFRE ( $\left.n^{\circ} 2019 / 0393\right)$.

\section{Authors' contributions}

Conceptualization and design of field observations: SB, KCM; Acquisition of data: PW, MJ, SB, AA, LB, AC, JFC, ND, TH, FH, NK, IL, AMd, AMr, SM, OP, TP, VP, MRM, MVT, HV, NC, GV, KCM; Statistical analysis and interpretation of data: PW, MJ, SB, KCM; Drafting the manuscript: PW, MJ, SB, GV, KCM; All authors revised and approved the final manuscript.

\section{Data availability}

The datasets generated during and/or analysed during the current study are available from the corresponding author on reasonable request.

\section{Conflict of interest}

The authors declare no conflict of interest. 


\section{References}

1. IPCC. Climate Change 2014: Impacts, Adaptation, and Vulnerability. Part A: Global and Sectoral Aspects. Contribution of Working Group II to the Fifth Assessment Report of the Intergovernmental Panel on Climate Change. (2014).

2. Gilbert, L. The Impacts of Climate Change on Ticks and Tick-Borne Disease Risk. Annu. Rev. Entomol. 66, 273-288 (2021).

3. Ostfeld, R. S. \& Brunner, J. L. Climate change and Ixodes tick-borne diseases of humans. Philos. Trans. R. Soc. B Biol. Sci. 370, 1-11 (2015).

4. Ogden, N. H. \& Lindsay, L. R. Effects of Climate and Climate Change on Vectors and Vector-Borne Diseases: Ticks Are Different. Trends Parasitol. 32, 646656 (2016).

5. Needham, G. R. \& Teel, P. D. Off-host physiological ecology of ixodid ticks. Annu. Rev. Entomol. 36, 659-681 (1991).

6. Milne, A. The ecology of the sheep tick, Ixodes ricinus L.:Microhabitat economy of the adult tick. Parasitology 40, 14-34 (1950).

7. Wongnak, P. et al. A hierarchical Bayesian approach for incorporating expert opinions into parametric survival models: A case study of female Ixodes ricinus ticks exposed to various temperature and relative humidity conditions. Ecol. Modell. 464, (2022).

8. Morellet, N. et al. Seasonality, weather and climate affect home range size in roe deer across a wide latitudinal gradient within Europe. J. Anim. Ecol. 82, 1326-1339 (2013).

9. Sagurova, I. et al. Predicted northward expansion of the geographic range of the tick vector amblyomma americanum in North America under future climate conditions. Environ. Health Perspect. 127, 1-14 (2019).

10. Ogden, N. H., Beard, C. Ben, Ginsberg, H. S. \& Tsao, J. I. Possible effects of climate change on ixodid ticks and the pathogens they transmit: Predictions and observations. J. Med. Entomol. 58, 1536-1545 (2021).

11. Macdonald, A. J., Mccomb, S., O’Neill, C., Padgett, K. A. \& Larsen, A. E. Projected climate and land use change alter western blacklegged tick phenology, seasonal host-seeking suitability and human encounter risk in California. Glob. Chang. Biol. 26, 5459-5474 (2020).

12. European Centre for Disease Prevention and Control. Ixodes ricinus - current known distribution: March 2021. (2021). Available at: https://www.ecdc.europa.eu/en/publications-data/ixodes-ricinus-current-known-distribution-march-2021. (Accessed: 20th July 2021)

13. Alonso-Carné, J., García-Martín, A. \& Estrada-Peña, A. Modelling the Phenological Relationships of Questing Immature Ixodes ricinus (Ixodidae) Using Temperature and NDVI Data. Zoonoses Public Health 63, 40-52 (2016).

14. Brugger, K., Walter, M., Chitimia-Dobler, L., Dobler, G. \& Rubel, F. Seasonal cycles of the TBE and Lyme borreliosis vector Ixodes ricinus modelled with timelagged and interval-averaged predictors. Exp. Appl. Acarol. 73, 439-450 (2017).

15. Hauser, G. et al. Influence of climatic factors on Ixodes ricinus nymph abundance and phenology over a long-term monthly observation in Switzerland (2000-2014). Parasites and Vectors 11, 1-12 (2018).

16. Bregnard, C. et al. Beech tree masting explains the inter - annual variation in the fall and spring peaks of Ixodes ricinus ticks with different time lags. Parasit. Vectors 14, 1-26 (2021).

17. Korenberg, E. I. Seasonal population dynamics of Ixodes ticks and tick-borne encephalitis virus. Exp. Appl. Acarol. 24, 665-681 (2000).

18. Weber, M. M., Stevens, R. D., Diniz-filho, J. A. F. \& Grelle, C. E. V. Is there a correlation between abundance and environmental suitability derived from ecological niche modelling? A meta-analysis. Ecography (Cop.). 40, 817-828 (2017).

19. Agoulon, A. et al. A vegetation index qualifying pasture edges is related to Ixodes ricinus density and to Babesia divergens seroprevalence in dairy cattle herds. Vet. Parasitol. 185, 101-109 (2012).

20. Boehnke, D. et al. Estimating Ixodes ricinus densities on the landscape scale. Int. J. Health Geogr. 14, 1-12 (2015).

21. Perez, G. et al. Effect of landscape features on the relationship between Ixodes ricinus ticks and their small mammal hosts. Parasites and Vectors $9,1-18$ (2016).

22. Hauck, D., Springer, A., Chitimia-Dobler, L. \& Strube, C. Two-year monitoring of tick abundance and influencing factors in an urban area (city of Hanover, Germany). Ticks Tick. Borne. Dis. 11, 101464 (2020).

23. Nyrhilä, S., Sormunen, J. J., Mäkelä, S. \& Sippola, E. One out of ten: low sampling effıciency of cloth dragging challenges abundance estimates of questing ticks. Exp. Appl. Acarol. 82, 571-585 (2020).

24. Bord, S., Druilhet, P., Gasqui, P., Abrial, D. \& Vourc'h, G. Bayesian estimation of abundance based on removal sampling under weak assumption of closed population with catchability depending on environmental conditions. Application to tick abundance. Ecol. Modell. 274, 72-79 (2014).

25. Santé Publique France. Borréliose de lyme. (2021). Available at: https://www.santepubliquefrance.fr/maladies-et-traumatismes/maladies-a-transmissionvectorielle/borreliose-de-lyme/donnees/\#tabs. (Accessed: 20th July 2021)

26. Joly, D. et al. Les types de climats en France, une construction spatiale. CyberGeo 2010, 2-22 (2010).

27. Lebert, I. et al. Distribution of ticks, tick-borne pathogens and the associated local environmental factors including small mammals and livestock, in two French agricultural sites : the OSCAR database. Biodivers. Data J. 8, (2020).

28. Vassallo, M., Pichon, B., Cabaret, J., Figureau, C. \& Pérez-Eid, C. Methodology for sampling questing nymphs of Ixodes ricinus (Acari: Ixodidae), the principal vector of Lyme disease in Europe. J. Med. Entomol. 37, 335-339 (2000).

29. Pérez-Eid, C. Les tiques: identification, biologie, importance médicale et vétérinaire. (Tec \& Doc Lavoisier, 2007).

30. Hijmans, R. J. geosphere: Spherical Trigonometry. R package version 1.5-10. (2019).

31. van Buuren, S. \& Groothuis-Oudshoorn, K. mice: Multivariate imputation by chained equations in R. J. Stat. Softw. 45, 1-67 (2011).

32. QGIS Development Team. QGIS Geographic Information System. (2021).

Page $11 / 18$ 
33. NASA JPL. NASA Shuttle Radar Topography Mission Global 1 arc second. NASA EOSDIS Land Processes DAAC (2013). doi:https://doi.org/10.5067/MEaSUREs/SRTM/SRTMGL1.003

34. FAO. Elements Of Topography. in Irrigation Water Management: Training Manual No. 1 - Introduction to Irrigation (Food and Agriculture Organization of the United Nations, 1985).

35. Fick, S. E. \& Hijmans, R. J. WorldClim 2: new 1-km spatial resolution climate surfaces for global land areas. Int. J. Climatol. 37, 4302-4315 (2017).

36. European Environmental Agency. Corine Land Cover (CLC) 2018, Version 2020_20u1. (2019). Available at: https://land.copernicus.eu/paneuropean/corine-land-cover/clc2018.

37. L'Institut national de l'information géographique et forestière. BD Forêt version 2. (2019). Available at: https://inventaire-forestier.ign.fr/spip.php? article646.

38. Shannon, C. E. A mathematical theory of communication. Bell Syst. Tech. J. 27, 379-423 (1948).

39. Panagos, P., Van Liedekerke, M., Jones, A. \& Montanarella, L. European Soil Data Centre: Response to European policy support and public data requirements. Land use policy 29, 329-338 (2012).

40. R Core Team. A Language and Environment for Statistical Computing. R Foundation for Statistical Computing 2, https://www.R-project.org (2019).

41. Brooks, M. E. et al. glmmTMB balances speed and flexibility among packages for zero-inflated generalized linear mixed modeling. $R$ J. 9, 378-400 (2017).

42. Lê, S., Josse, J. \& Francois, H. FactoMineR: A Package for Multivariate Analysis. J. Stat. Softw. 25, 1-18 (2008).

43. Kassambara, A. \& Mundt, F. factoextra: Extract and Visualize the Results of Multivariate Data Analyses. (2020).

44. Barton, K. MuMIn: Multi-Model Inference. (2020).

45. Hartig, F. DHARMa: Residual Diagnostics for Hierarchical (Multi-Level / Mixed) Regression Models. (2020).

46. Feng, C., Li, L. \& Sadeghpour, A. A comparison of residual diagnosis tools for diagnosing regression models for count data. BMC Med. Res. Methodol. 20, $1-21$ (2020).

47. Fox, J. \& Weisberg, S. An R Companion to Applied Regression. (Thousand Oaks, CA, 2019).

48. Mejlon, H. A. Diel activity of Ixodes ricinus Acari: Ixodidae at two locations near Stockholm, Sweden. Exp. Appl. Acarol. 21, 247-256 (1997).

49. Kjellander, P. L., Aronsson, M., Bergvall, U. A. \& Carrasco, J. L. Validating a common tick survey method: cloth - dragging and line transects. Exp. Appl. Acarol. 83, 131-146 (2021).

50. Cayol, C., Koskela, E., Mappes, T., Siukkola, A. \& Kallio, E. R. Temporal dynamics of the tick Ixodes ricinus in northern Europe: epidemiological implications. Parasit. Vectors 10, 1-11 (2017).

51. Poli, P. et al. Strong genetic structure among populations of the tick Ixodes ricinus across its range. Ticks Tick. Borne. Dis. 11, 101509 (2020).

52. Tomkins, J. L., Aungier, J., Hazel, W. \& Gilbert, L. Towards an evolutionary understanding of questing behaviour in the tick Ixodes ricinus. PLoS One 9 , e110028 (2014).

53. Bregnard, C., Rais, O. \& Voordouw, M. J. Climate and tree seed production predict the abundance of the European Lyme disease vector over a 15-year period. Parasites and Vectors 13,1-12 (2020).

54. Ogden, N. H. \& Lindsay, L. R. Effects of Climate and Climate Change on Vectors and Vector-Borne Diseases: Ticks Are Different. Trends Parasitol. 32, 646656 (2016).

55. Belozerov, V. Diapause and Biological Rhythms in Ticks. in Physiology of Ticks (eds. Obenchain, F. D. \& Galun, R.) $469-500$ (Pergamon, 1982). doi:10.1016/b978-0-08-024937-7.50018-4

56. Li, S., Heyman, P., Cochez, C., Simons, L. \& Vanwambeke, S. O. A multi-level analysis of the relationship between environmental factors and questing Ixodes ricinus dynamics in Belgium. Parasites and Vectors 5, 1-11 (2012).

57. Tack, W. et al. Local habitat and landscape affect lxodes ricinus tick abundances in forests on poor, sandy soils. For. Ecol. Manage. 265, 30-36 (2012).

58. Perez, G. et al. Relationships between landscape structure and the prevalence of two tick-borne infectious agents, Anaplasma phagocytophilum and Borrelia burgdorferi sensu lato, in small mammal communities. Landsc. Ecol. 35, 435-451 (2020).

59. Malagnino, A. et al. Do reproductive constraints or experience drive age-dependent space use in two large herbivores ? Anim. Behav. 172, 121-133 (2021).

60. Li, S., Hartemink, N., Speybroeck, N. \& Vanwambeke, S. O. Consequences of landscape fragmentation on Lyme disease risk: A cellular automata approach. PLoS One 7, (2012).

61. Halos, L. et al. Ecological factors characterizing the prevalence of bacterial tick-borne pathogens in Ixodes ricinus ticks in pastures and woodlands. Appl. Environ. Microbiol. 76, 4413-4420 (2010).

62. De Keukeleire, M. et al. Scouts, forests, and ticks: Impact of landscapes on human-tick contacts. Ticks Tick. Borne. Dis. 6, 636-644 (2015).

63. Ogrzewalska, M., Uezu, A., Jenkins, C. N. \& Labruna, M. B. Effect of forest fragmentation on tick infestations of birds and tick infection rates by Rickettsia in the Atlantic Forest of Brazil. Ecohealth 8, 320-331 (2011).

\section{Figures}




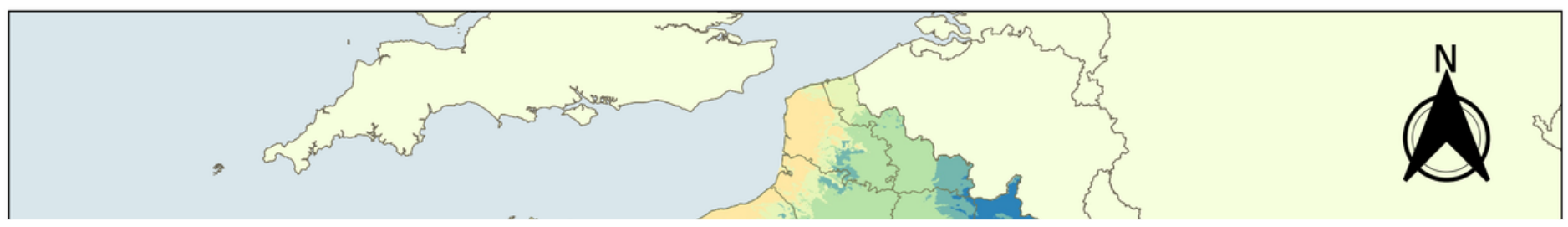

\section{Figure 1}

The distribution of tick observatories according to the climatic region types of the continental France $\left.{ }^{26}: 1\right)$ Etiolles (degraded oceanic); 2) Velaine-en-Haye (semi-continental); 3) Les Bordes (degraded oceanic); 4) Carquefou (oceanic); 5) La Tour de Salvagny (mixed); 6) Saint-Genès-Champanelle (mountain); 7) Gardouch (south-west basin). 
A Monthly average temperature

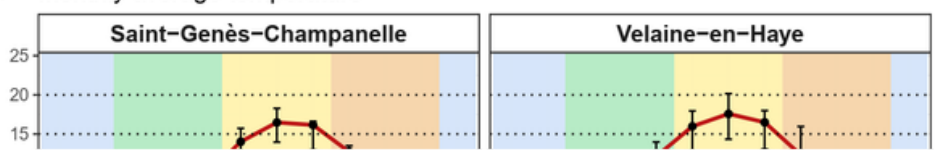

B Monthly average minimum relative humidity

\begin{tabular}{|c|c|c|}
\hline & Saint-Genès-Champanelle & Velaine-en-Haye \\
\hline
\end{tabular}

\section{Figure 2}

Monthly average meteorological conditions of 7 tick observatories: A) Average temperature ; B) Minimum relative humidity . The average values were calculated using the imputed data from January 2013 to June 2021, with the exception of Les Bordes, which was calculated from January 2017 to June 2021. The points represented the median of the monthly average values over the observed period, while the error bars represent the maximum and minimum monthly average values. Background colours indicated meteorological seasons of the northern hemisphere: Spring, $1^{\text {st }}$ March to $31^{\text {st }}$ May (green); Summer, $1^{\text {st }}$ June to $31^{\text {st }}$ August (yellow); Autumn, $1^{\text {st }}$ September to $30^{\text {th }}$ November (brown); Winter, $1^{\text {st }}$ December to $28^{\text {th }}$ February (blue). 
A Variables - PCA

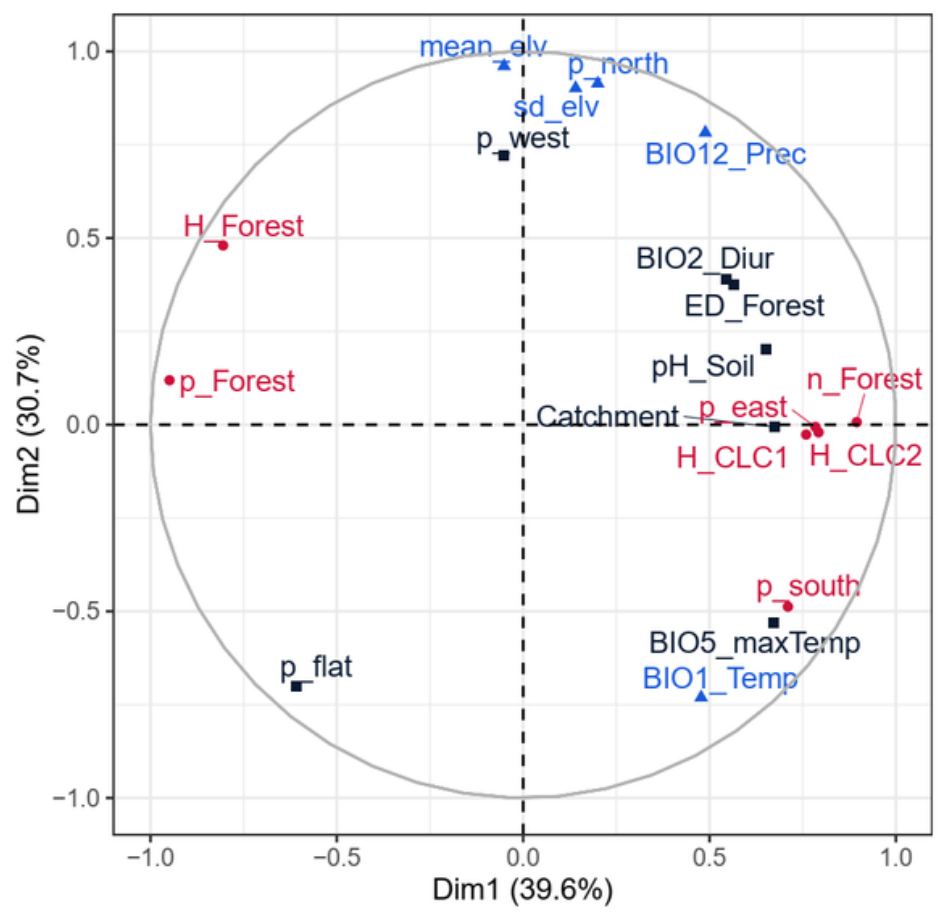

B Individuals - PCA

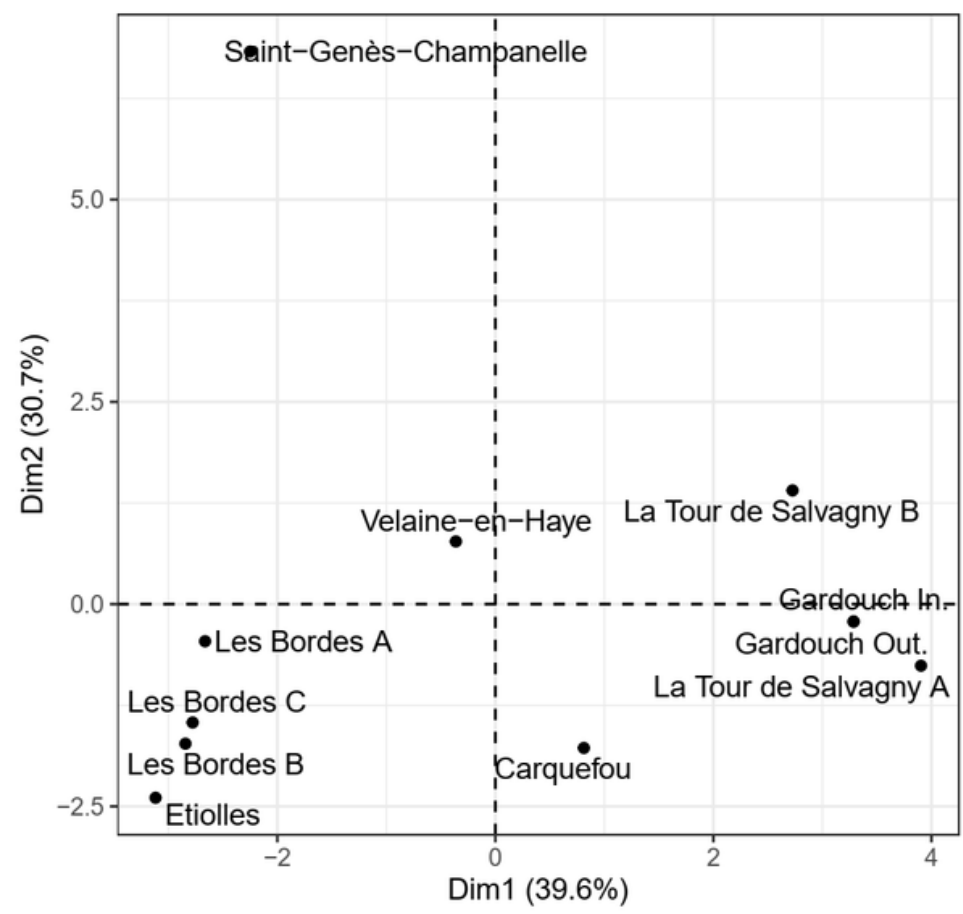

Figure 3

Principal component analysis (PCA) for land cover, topography, and bioclimate characteristics of all sampling sites: A) PCA plot for land cover, topographical, and bioclimatic variables. Colours indicate whether the variable contributes more to Dimension 1 (red), Dimension 2 (blue), or other higher dimensions (black), using the cumulative contribution of $\sim 60 \%$; B) PCA plot for individual sampling sites. Coordinates of the individual PCA plot were subsequently used in the regression analysis. 


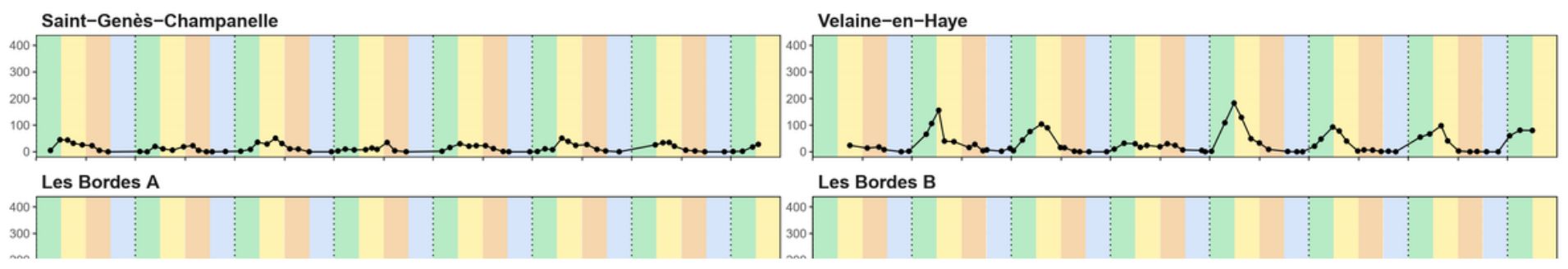

\section{Figure 4}

Number of Ixodes ricinus nymphs per $100 \mathrm{~m}^{2}$ obtained from 11 sampling sites. Background colours indicate meteorological seasons of the northern hemisphere: Spring, $1^{\text {st }}$ March to $31^{\text {st }}$ May (green); Summer, $1^{\text {st }}$ June to $31^{\text {st }}$ August (yellow); Autumn, $1^{\text {st }}$ September to $30^{\text {th }}$ November (brown); Winter, $1^{\text {st }}$ December to $28^{\text {th }}$ February (blue). Vertical dashed lines indicate 1-year interval. 

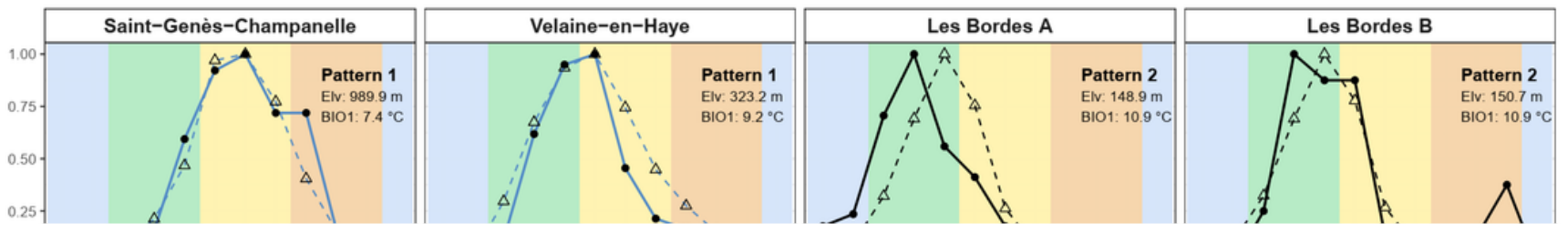

\section{Figure 5}

Observed and predicted normalized median nymph counts of each sampling site by month; the values of 0 and 1 indicate minimum and maximum normalized median nymph count, respectively. Line types distinguish between the observation (solid) and prediction from the best-fitted model (dashed). Line colours indicate different phenology patterns of the observed data: Pattern 1, a unimodal pattern with a summer peak and a winter pause (blue); Pattern 2, a bimodal pattern with a greater activity peak in spring and a smaller peak in autumn (black); Pattern 3, a unimodal pattern with a spring peak without winter pause (red). Text annotations demonstrate mean elevation above the sea level $(\mathrm{m})$ and average annual temperature $\left({ }^{\circ} \mathrm{C}\right)$. Numbers at the bottom represent the number of observations of each month throughout the study period. Background colours indicate meteorological seasons of the northern hemisphere: Spring, $1^{\text {st }}$ March to $31^{\text {st }}$ May (green); Summer, $1^{\text {st }}$ June to $31^{\text {st }}$ August (yellow); Autumn, $1^{\text {st }}$ September to $30^{\text {th }}$ November (brown); Winter, $1^{\text {st }}$ December to $28^{\text {th }}$ February (blue). 
One-month average temperature, $\mathrm{T}_{\mathrm{M}}^{0: 1}$
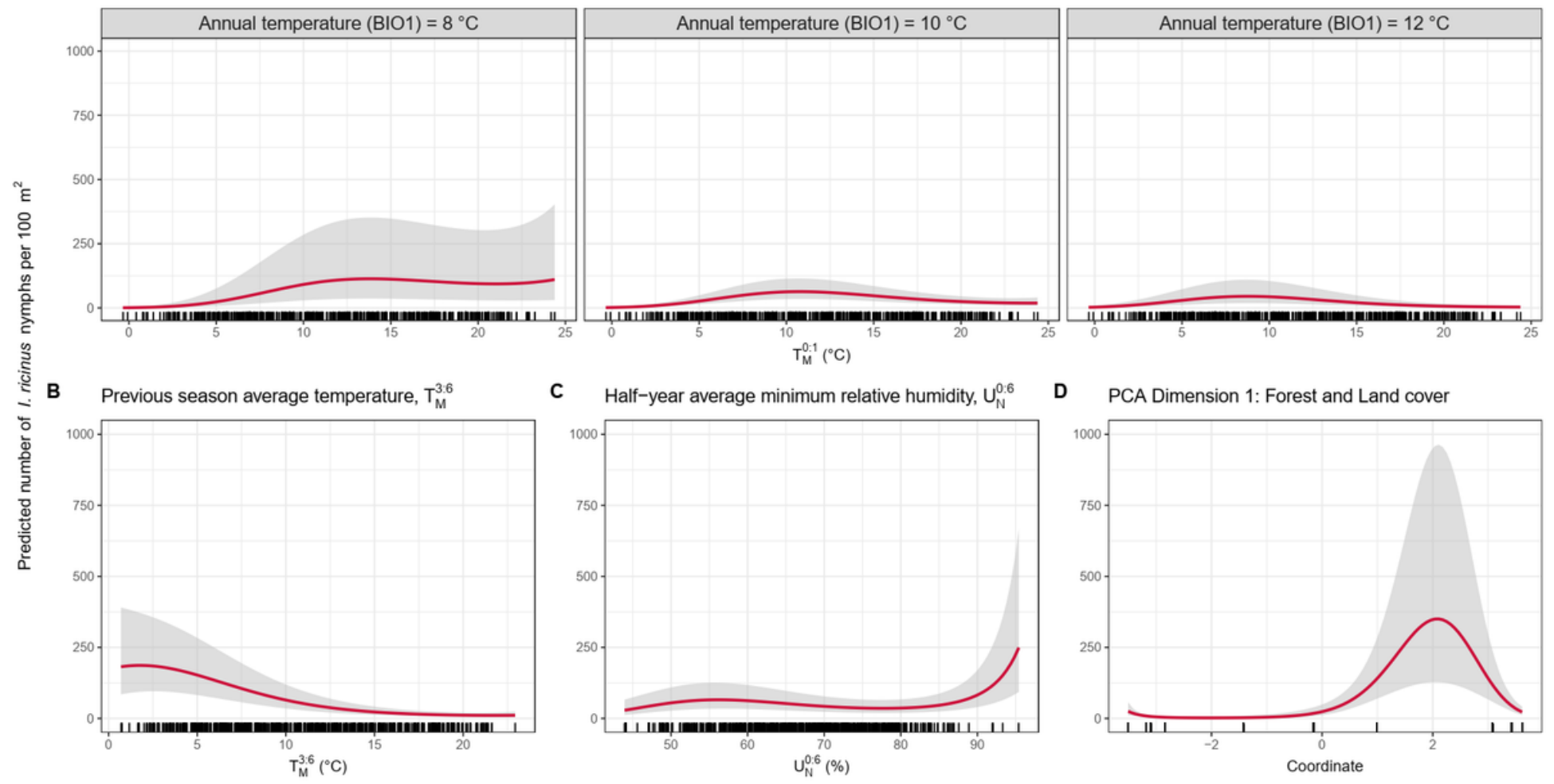

C

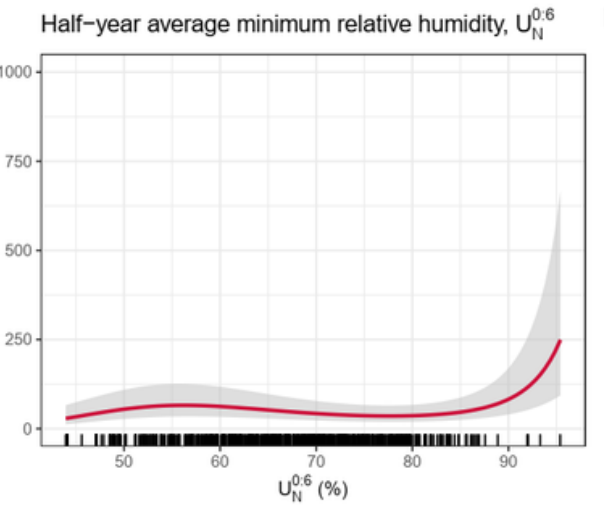

D PCA Dimension 1: Forest and Land cover

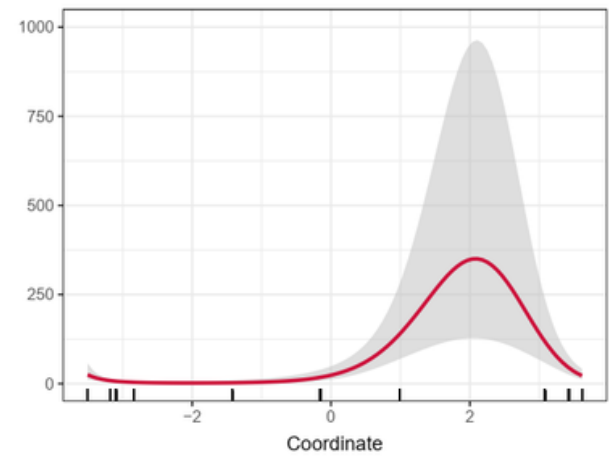

Figure 6

Predicted effects of environmental factors on the number of $I$. ricinus nymphs per $100 \mathrm{~m}^{2}$ given the average values of all other variables: A) One-month average temperature, an averaged mean temperature between previous 30 days and sampling day ( ) with an interaction effect with annual temperature ( ); B) Previous season average temperature, an averaged mean temperature between 3 to 6 months prior to the sampling day ( ), C) Half-year average minimum relative humidity, an averaged minimum relative humidity between previous 6 months and the sampling day ( ); D) Coordinates on Dimension 1 of the principal component analysis ( ), representing forest and land cover characteristics. Gray shaded areas indicate a 95\% confidence interval. Rugs display the distribution of observed values.

\section{Supplementary Files}

This is a list of supplementary files associated with this preprint. Click to download.

- SupplementaryClimaticActivity211222.docx 